\title{
Do Collaborative Relationships in Supply Chain Pay-Off?
}

\author{
Ik-Whan G. Kwon, St. Louis University, St. Louis, MO, USA \\ Seock-Jin Hong, University of North Texas, Denton, TX, USA \\ Sung-Ho Kim, Yonsei University, Seoul, South Korea
}

Collaborative relationship is said to foster sustainable supply chain operations. It is argued that relationship based supply chain produces financially tangible results in many areas of supply chain. The concept is based on transaction cost theory arguing that the final price is determined in the market by total cost. A collaborative relationship fosters trust that leads to lowering transaction cost and speed up time to market which creates "serial equity" rather than "spot equity". Recent research on collaboration and supply chain performance seems to suggest tangible financial gains. Yet, no theoretical framework has been developed and empirical evidences have been lacking to support such hypothesis. A clearly defined theoretical framework and supportive empirical evidence between these two constructs are needed for future research in this area. This article attempts to articulate the theoretical foundation of collaborative relationship in supply chain and survey empirical results on financial gains reported in various research studies.

\section{KEYWORDS}

Cloud-based Supply Chain, Commitment, SC Foundation, Supply Chain Financing, Supply Chain Optimization, Transaction Cost

\section{INTRODUCTION}

One of the main objectives for supply chain is to create financial "surplus" for every participant in the supply chain community. The weakest supply chain link has to be addressed before the community "surplus" is considered possible. If the weakest link is left unaddressed, the maximum supply chain surplus cannot be materialized and everyone in the link becomes a "loser" from the operations.

The main source for poor supply chain performance operations is a weak foundation for supply chain structure. Kwon, Hamilton and Hong (2011) argue that a successful supply chain requires three stages in its structure; foundation, tools/engines and ultimate reward (financial returns). The goal for supply chain management is to improve the profitability for all partners within the supply chain. However, such goal may not be achieved or even feasible if the supply chain foundation is not firmly established. Research indicates that business transactions become efficient (cost saving) and effective (customer responsiveness) once commitment is established (Barney and Hansen, 1994; Dyer, 1997). Commitment, however, is seldom enforced unless a certain level of trust between supply chain partners is formed (Kwon and Suh, 2005). Collaboration among supply chain partners is the first step to establish such trust. A collaborative relationship is a long-term, win-win partnership among organizations based on joint value creation for the supply chain network focused on the end-customer needs. This type of supply chain is based on trust. Collaboration encourages two or more enterprises (or persons) working closely together to achieve shared strategic goals that produce greater values for all parties than could be gained by acting alone. Information sharing is a first step toward establishing 
a collaborative relationship. In short, information sharing creates environment that fosters collaborative framework, which, in turn, opens the door for trust building process.

Accordingly, it is reasonable to stipulate that trust and information sharing are central tenets of supply chains. When not fully integrated because of lack of trust, or information sharing, the transaction costs of doing business increase and the ability to respond to potential risk/disruption diminishes (Eshkenazi, 2009). Some researchers even argue that one of the reasons for limiting collaboration among supply chain partners is the lack of trust amongst each other (Fawcett, et al., 2009).

The premise of collaboration in supply chain performance improvement is that supply chain collaboration should look at developing close working relationships with customers and suppliers. Should these collaborative efforts succeed, then it is reasonable to expect performance improvements. For example, Simatupang and Sridharan (2005) show that there is a strong correlation $\left(\mathrm{R}^{2}=0.74\right.$, $\mathrm{p}<0.01$ ) between a collaboration index (measured by degree of information sharing, degree of decision synchronization, and degree of incentive alignment) and the performance index (measured by fulfillment rate, inventory turnover, and responsiveness). Their argument seems to be supported in a more recent study by Henke, et al. (2014) who measured the relationship between revenue per vehicle and trust index. Still another research study further indicates that firms in supply chains with high levels of collaboration have a greater competitive advantage than those in less collaborative supply chains (Themistcloeous, et al, 2004; Myhe and Speckman, 2005). The supply chain operation in a typical case starts with cooperation (to capture extra benefits) which may lead to collaboration (to create future value) which in turn creates an environment conducive to building trust with trading partners where business transactions actually are consummated (Kwon and Suh, 2004).

The purpose of this study is to explore the theoretical framework where and how collaboration leads to financial improvement for all supply chain participants. Empirical results reported in research publications should support our theoretical framework. This article consists of literature review, theoretical foundation, empirical results, summary and conclusions and managerial implications.

\section{LITERATURE REVIEW}

There has been some confusion as to the terms of collaboration, coordination and cooperation. Coordination implies that "I do it because I am told to do so". No feeling and no vision. Cooperation, on the other hand, carries the implication that "I do it because I see immediate benefits for me" (spot equity). Finally, for collaboration, "I do it because I see a long-term value for me and for my organization" that fosters creating trust and produces "serial equity" as opposed to "spot equity" (Pekman, et al., 1998). Collaboration, therefore, suggests two or more enterprises (or persons) working closely together to achieve shared strategic goals that produce greater values for all parties than could be gained by acting alone (Monczka, 2014). The characteristics of collaboration, therefore, are deep, intensive communication among the partners, open and free information sharing, and some form of joint planning including mutually shared goals (Stallkamp, 2005).

Strategic collaborators are those partners in a supply chain who are closely aligned in their long-term business strategy and shared values. Together, both parties are making complimentary investments in technology, intellectual property, and new products. With each of the partners in this supply chain so directly relying on the performance of the others, maximum information sharing is desired and needed, and is so stipulated in governance agreements (Giguere and Householder, 2012). At the end of the day, supply chain management is about relationship management. A supply chain is managed; link-by-link, relationship-by-relationship, and the organizations that manage these 
relationships best will survive. It is even claimed that supply chain operations start from and end with their relationship (Lambert, et al., 2001).

Research, however, shows, that only 2 out of 10 collaborative ventures deliver significant results due largely to lack of firm understanding of the supply chain foundation (Benavides and Swan, 2012). Supply chain is dynamic, complex and global. It requires an innovative idea and approach to meeting these challenges. Failure of entertaining these challenges create an illusion that supply chain solves everything only to face disappointing consequences in financial as well as the emotional side of management. Fostering supply chain relationships with a foundation in trust takes time and effort, but the rewards are well worth the effort. Trust makes the supply chain more responsive to a business's demands through decreasing the transactional costs of the search of information, negotiations, and monitoring of the supply chain progress. On the other hand, an adversarial approach may result in lower supply chain trust, which in turn reduces the supplier's willingness for price concession that is quite an opposite effect as shown in Chrysler experiences (Henke, John Jr., et al., 2014). The same study describes non-price incentives contribution by suppliers when trust is established that include: increased supplier willingness to share new product and process innovation ideas with the customers, increased supplier willingness to invest in customer specific new product and process innovation in anticipation of future customer needs, suppler willingness to allocate greater resources and the most qualified personnel to support the customers, and more open and honest supplier communication with the customer.

A study by Handfield and Bechtel (2002, p.375) on supplier relationship management and trust shows that "buyers ultimately put more faith on the supplier's actions, rather than its conformance to a legal document". Minor violations of contracts tend not to lead to litigations, but the minor violations on trust can cause damage to a supplier's reputation. Another factor that affects collaborative relationship is a buyer's dependence on a supplier. This dependence is thought to have a negative effect on trust, because a buyer is believed to be defenseless against unfair terms especially when depending on few suppliers. The most effective way to increase trust is through the investment of site specific assets (Suh and Kwon, 2003). A site specific asset can be customized information sharing systems, specific equipment, increased capacity, and/or tailored customer support (Handfield and Bechtel, 2002). Investing in these types of specific assets demonstrate the desire for a long-term relationship. It signals to the customers/buyers that the supplier is ready to adapt to better suit their needs and is a physical reminder of their commitment to them. Without the buyer-seller relationship, the customized asset has no viable value, and the supplier will take a loss on its investment. Suppliers that take this risk, generally gain a customer's trust in their ability to perform. When risks are taken, trust is built, and the overall supply chain becomes more responsive. Handfield and Bechtel study (2002) confirms that trust makes a more responsive supply chain because formal safeguards can be relaxed and suppliers go beyond written agreements if the relationship is vested in trust. The reliance on informal contracts decreases transactional costs of negotiations, because the buyer and sellers trust in each other's ability to perform. As a result, the supply chain is less entangled by complex formal contract and regulations, and becomes more responsive. Benefits increase for both parties (suppliers and buyer).

Another study by Kwon and Suh (2004) in a similar vein dives deeper into the relationship between transaction cost and the level of trust. In addition to site specific assets investment and information sharing, a business partner's behavioral uncertainty is essential aspects of trust in supply chain relationships. The search for information is a large component of transactional cost. Firms can spend significant amounts of resources to obtain information from $3^{\text {rd }}$ party sources. Open flows of information throughout the supply chain prevent devastating consequences, like stock-out and the bull whip effect (Kwon and Suh, 2004). Information exchange among partners also serves to reduce the amount of behavior uncertainty. Behavior uncertainty is the incapacity to see how a partner will react to shifts in the external environment. Uncertainty in a partner's behavior will cause a firm to monitor their partner's actions thoroughly. As a result, behavior uncertainty has a negative effect on 
trust in a supply chain relationship. The mediating role of information sharing on behavior uncertainty increases the level of trust within a partnership. With a supply chain partnership founded in trust through the practice of information sharing, the transactional costs of monitoring and the search for information decrease.

A recent development of cloud-based supply chain adds another dimension to supply chain operations (Chang and Wills, 2013). Cloud-based supply chain has created an interconnected world that goes beyond the communications of the early ages of the internet and Web 2.0 that influences the way supply chain world behaves. Suppliers and customers constantly communicate to minimize and/or remove any uncertainty, a basic source of dis-trust. For supply chain executions, there is no room for error which would create a perceived dis-trust. Any error along the supply chain generates a bull-whip effects that distorts any optimization plan. Such distrust makes players tempting localized optimization rather than global optimization which destroys the total (global) supply chain surplus. A closer connectivity with suppliers and customers via cloud-based supply chain makes relation building process easier, quicker and intimate creating opportunity to strengthen supply chain foundation. A use of cloud-based supply chain helps to motivate customers improves learning satisfaction (Chang and Wills, 2013).

The cloud-based supply chain is affordable in cost as economies of scale kicks in when more players join in this network. Software in cloud-computing is fully capable of integration with the existing IT software that eliminates or minimizes any duplicated installing cost. Cloud-based supply chain solution has more redundancy that is far less likely to suffer damage than local solutions. Finally cloud-based supply chain is efficient in that the software provides the ability of management team to make the most informed decisions with a minimum strain on the budget or time of current workforce (Robinson, 2015).

Research also indicates that business transactions become efficient and effective once commitment to trust is established (Barney and Hansen, 1994; Dyer, 1997). Commitment, however, is seldom realized unless a certain level of trust between and among supply chain partners is formed. Collaboration between supply chain partners is the first step to establish such trust. A collaborative relationship is a long-term, win-win partnership between organizations based on joint value creation for the supply chain network focused on the end-customer needs. Once trust and commitment are firmly established, speed to the market is accelerated that captures a bigger market share in a global scale (Covey, 2008).

When commitment is honored under such a positive environment, the transaction cost is set to decrease noticeably because trust allows each party to act in good faith, thereby skipping such tedious transactional activities as checking the accuracy of invoices, quality of products, endless communications to resolve difference, and discrepancies etc., (Dyer and Chu, 2003). As trust within and outside an organization improve the speed of decision making also increases and costs of making timely decisions, therefore, decrease. For example, end-to-end collaboration in supply chain activities provided a 30\% saving in administrative cost (Duffy, 2009; Dyer and Chu, 2003). A study by Xie, Suh and Kwon (2010) concluded that transaction cost and financial investment constructs have a strong relationship with continuance and behavioral commitment. A close collaboration with a selected partner is cited as one of the 10 most critical strategies for leading supply chain organizations (Poirier, et al., 2010). A strong positive correlation $\left(\mathrm{R}^{2}=0.69, \mathrm{p}<0.05\right)$ was reported between the degree of collaboration with suppliers and profitability in the automobile industry (Poirier, et al., 2010). On the other hand, a lack of trust among and between trading partners is cited as one of the most important barrier for supply chain excellence (Fawcett, et al., 2009). It is also reported that "truly collaboration trading partner relationships significantly reduces costs, mitigate risk, improve innovation, accelerate problem solving and yield a 50\% steeper organizational learning curve as measured against gains in any operating metrics." (O’Marah, 2012, p.4).

A recent study also highlights that trust based supply chain builds social capital which in turn creates value for partners and consumers as a whole (McGrath and Sparke, 2005). Therefore, 
trust-based supply chain creates social/consumer surplus where every consumer in society benefits (consumer surplus). Whitney (1994) even venture to say that mistrust doubles the cost of doing business. Supplier price concessions and non-price benefits, such as suppliers' willingness to share new process and product innovation ideas increase as trusting work relations increase (Henke, et al., 2014). The same study asserts that a company's actions toward its suppliers substantially affect the suppliers' contribution to the company's profitability. This notion was contrary to the common domestic automotive industry belief, according to the authors, in that increasing supplier trust and getting a greater supplier price reductions were mutually exclusive.

Research also shows that a collaborative relationship has even extended to their competitors to take advantage of competitors' strength that could enhance their own overall financial gains. For example, Samsung Electronics has been supplying its latest solid-state drives (SSD) to Apple for its latest MacBook Air since April, 2013, according to industry sources (Yahoo News June 17, 2013). The news came as a surprise as the U.S. technology giant has vowed to cut its reliance on its Korean rival amid their seemingly endless patent legal battles. Samsung and Apple's relationship is not alone. Ford Motor has asked Hyundai Motor and other automakers to join its initiative in establishing software application development for connected cars (Korea Times, September 14, 2014). In the aerospace field, Lockheed Martin and Boeing teamed up on a \$55 billion long-range bomber program bid (St. Louis Business Journal, October 24, 2013). Paxco Industries, a large U.S. based energy management company and BigCo, a leading Chinese supplier had gone even further in their collaborative venture on an electronic control device (ECD) that includes product design, information sharing, materials requirements information sharing and executive-to-executive engagement (CAPS Research, 2013).

Literature on collaborative relationships in supply chain shows how trust is built through site specific assets, information sharing, and the reduction of behavioral uncertainty. With the mounting evidence in the academic research, trust based collaborative relationships seem to be an indispensable requirement for a successful supply chain.

\section{THEORETICAL FRAMEWORK FOR FINANCIAL GAINS FROM COLLABORATION}

First obvious result from trust-based collaboration is a lower supply chain cost through reduced transaction cost. The transaction cost theory originally advanced by Coase (1937) is how the final price of goods and services is determined in the market. The theory argues that the final (optimum) price is determined in the market by "total cost." Labor, materials and other related costs such as administrative cost, search for better information, etc. constitute "total cost." In some cases, the transaction cost is sizeable. Indeed, North (1990) estimates that transaction costs may represent as much as 35-40\% of the costs associated with economic activity. Transaction costs, therefore, involve all of the costs associated with conducting exchanges between firms and can be decomposed into ex ante transaction costs (search and contracting costs), and ex post contracting costs (monitoring and enforcement costs) (Williamson, 1981 and 2008; Cheung, 1987; North, 1990; Hennart, 1993; Tadelis, 2007). Search costs include the costs of locating a desirable trading partner and then negotiating and writing a mutually acceptable contract. Enforcement costs refer to the costs associated with monitoring the contract implementation and the procedures necessary to ensure that each party fulfills the predetermined set of obligations in the contracts. If partners spend more time up front negotiating a mutually acceptable agreement, it is possible that this may reduce monitoring and enforcement costs because all of the expectations and obligations will have been clearly specified during the contracting phase (Dyer and Chu, 2003). Accordingly, they argue that any investigation into a transaction cost should separate these two types of transaction costs.

Based on a literature review, it is reasonable to conceptualize a theoretical map outlining the relationship between trust-based collaborative relationship and the performance of financial results as outlined in Figure 1. 
Figure 1. Roadmap to sustainable supply chain operations

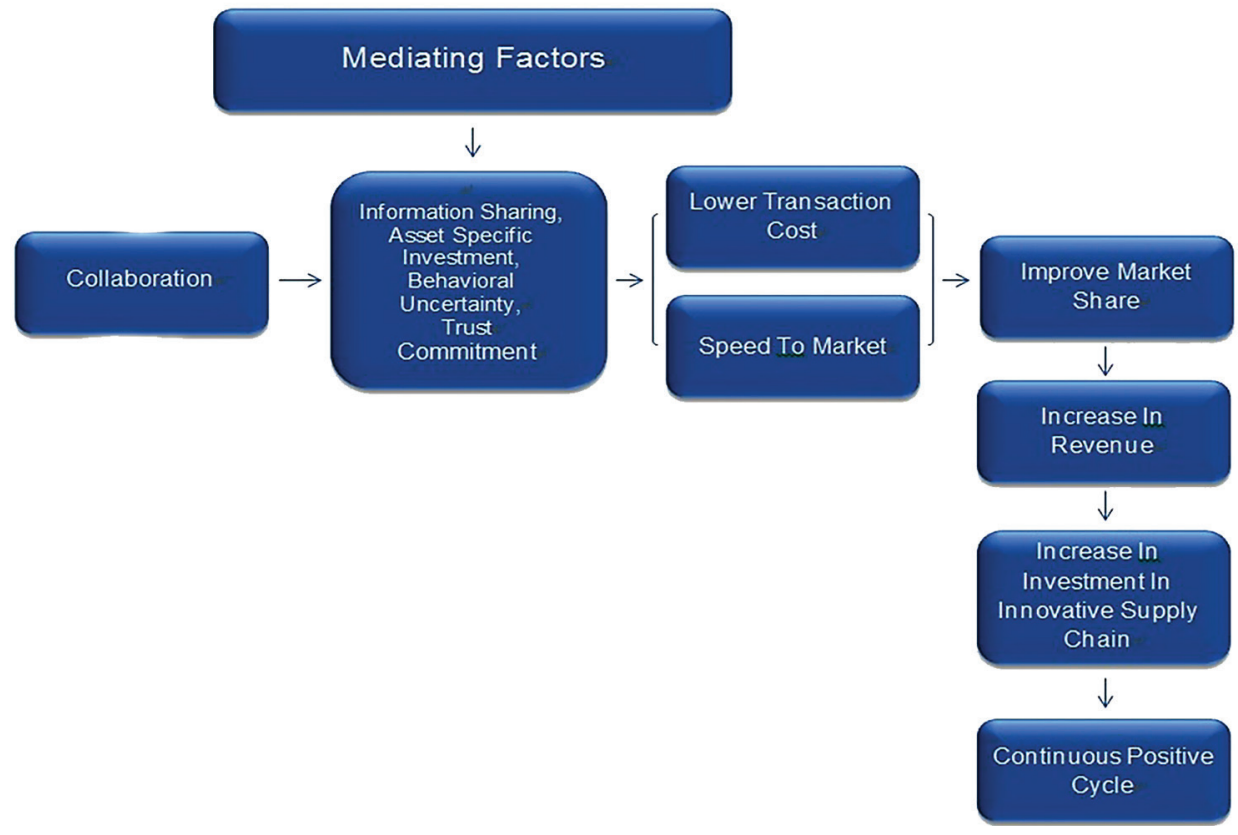

Our literature review suggests that collaboration encourages players to share supply chain related information (tactical, operational and strategic) because information sharing creates environments conducive for mutual financial gains. Information sharing also tends to minimize any opportunity for supply chain player's behavioral uncertainty and willing to invest customer's specific asset without fear that customers may negate the contract. Trust and commitment will be explored in search for a greater supply chain surplus.

Once such commitment is firmly established, two powerful processes start to kick in; cost reduction and speed to market. Trust and commitment nurture positive business environments where transactions become efficient and results oriented. It is natural to expect from this positive process that the cost of doing business (transaction cost) is lowered as there are no needs to have army of CPAs, lawyers, quality inspectors, etc. On the other hand, such leaner and simpler business transactions among trusted and committed business partners make it possible to speed their products/services to the market. Market share improves that also fosters enhancing product brand names in the market. The lower supply chain cost coupled with increase in market share via global brand name recognition improves the supply chain surplus for all participants. This surplus allows supply chain practitioners to invest their extra resources into innovative supply chain design and technologies that further enhances their performance. Investments into new technologies such as cloud computing enhance fulfillment and on-time delivery which further attract new customers and/or increase order quantity from the existing customers. The cycle will continue as long as the practitioners are vigilant to the fundamentals of supply chain principles; sharing information, benefit and risks (Kwon, et al., 2011). Sharing benefits with trading partners is one of the most important factors encouraging partners and even induce competitors to join collaborative relationship. For example, Scott Lee, former CEO at Wal-Mart announced in 1996 a target for all suppliers to reduce packaging by $5 \%$. This improvement is projected to save $\$ 10$ billion per year, with two-thirds of the saving went to suppliers (Ampula, et al., 2014). 


\section{EMPIRICAL RESULTS}

Literature review on collaborative relationships in supply chain seems to provide a convincing argument of a close link between relationship and supply chain cost reduction and provide us an opportunity to develop a theoretical model linking collaboration with supply chain performance. As described in the previous section, trust based collaboration with suppliers makes the supply chain more responsive to a customer's needs through decreasing the transactional costs of the search of information, negotiations, and monitoring of the supply chain. On the other hand, an adversarial approach may result in lower supply chain trust, which, in turn, reduces the supplier's willingness of price concession that is quite the opposite effect as shown in Chrysler's case. In addition to price reduction willingly provided to customers, non-price incentive contributions by suppliers cannot be ignored when trust is established that include: increased supplier willingness to share new product and process innovation ideas with the customers, increased supplier willingness to invest in customer specific new products and process innovation in anticipation of future customer needs, greater suppler willingness to allocate extra resources and the most qualified personnel to support customers, and, more open and honest supplier communication with the customer (Henke Jr., et al., 2014)

Table 1 summarizes research findings on relationship between the level of trust/collaboration and financial performances.

A survey of 145 finance professionals by the Aberdeen Group (Supplymanagement.com, 2011) found that enterprises which actively collaborate with executive management in their supply chain finance initiatives see both quantitative and qualitative benefits. For example, cash conversion - from invoice to payment - is four days shorter compared with other firms, the report found. According to the survey, the top 20 percent 'best in class' organizations processed invoices more rapidly than the rest of the field, but also managed to extend the days payable and received the lowest prices.

Cotton (2009) classifies the level of collaboration into three scales: basic, intermediate and advanced. The different scales are correlated with the return on capital (ROC) in six different business areas; human resources, $\mathrm{R} \& \mathrm{D}$, sales, marketing, investor relations and public relations. ROC for companies with advanced collaboration ranges from $4 \%$ in human resources to $8 \%$ in R\&D and Sales, while the same for companies with basic scale ranges only from $2 \%$ to $2.8 \%$.

Healthcare has been experiencing a rapid cost increase for the last several decades and supply chain has been cited as a possible strategic tool to manage the rising cost. Kwon and Hong (2011)

Table 1. Degree of collaboration and financial returns

\begin{tabular}{|c|c|c|}
\hline Sources & Unit/Areas Measurement & Results \\
\hline Cotton (2009) & Return of capital & $\begin{array}{l}4 \text { to } 8 \% \text { for top performers vs. } 2 \text { to } 2.8 \% \text { for the average } \\
\text { performers }\end{array}$ \\
\hline Duffy (2009) & Savings & $\begin{array}{l}\text { Companies with strong collaboration save better than average } \\
\text { collaborative companies in; } \\
10 \text { to } 20 \% \text { in inventory, } \\
20 \text { to } 30 \% \text { in admin cost } \\
3 \text { to } 8 \% \text { in logistics cost } \\
1 \text { to } 2 \% \text { in production cost } 1 \text { to } 2 \% \text { in general spends }\end{array}$ \\
\hline $\begin{array}{l}\text { Porrier, Quinn and } \\
\text { Swink (2010) }\end{array}$ & Profit per vehicle & $\begin{array}{l}\text { Nissan }(\$ 1,800) \text {, Toyota }(\$ 1,500) \text {, Honda }(\$ 1,200) \text {, Chrysler } \\
(\$ 300) \text {, Ford }(-\$ 200) \text { and GM }(-\$ 1,200)\end{array}$ \\
\hline $\begin{array}{l}\text { Aberden Group } \\
(2011)\end{array}$ & Better financial performance & $\begin{array}{l}\text { (1). For top companies, cash conversion cycle is } 4 \text { days faster, } \\
\text { (2). } 20 \% \text { faster in invoice process, ( } 3 \text { ) more extension of } \\
\text { amount payable, and (4) receive lower prices }\end{array}$ \\
\hline $\begin{array}{l}\text { Henke, Stalkemp \& } \\
\text { Tenivurt (2014) }\end{array}$ & Lost profit & Lost $\$ 24$ billion profit over 12 years \\
\hline
\end{tabular}


argue that the healthcare industry is far behind in using supply chain strategies compared to commercial industry in coping with rising costs. A recent publication by UPS (2015) concur the prevailing situation in healthcare supply chain. Their concerns were raised earlier and supported by a study that shows a significant savings from end-to-end collaboration (Dufy, 2009). The study shows that a strong end-to-end collaboration in healthcare providers create impressive savings for providers in inventory (range from 10 to $20 \%$ of the base price), administration (from 20 to 30\%), logistics (from 3 to $8 \%$ ), production (1 to $2 \%$ ) and spends (1 to $2 \%$ ).

The Japanese automobile industry has been known practicing supplier relationship management (SRM) for many years and it is superior to those in the American automotive industry. SRM is, in essence, a philosophy of mutual respect and cooperation between a company and its supplying firms, manifested by co-prosperity, a collaborative, two-way relationship that can deliver value for both parties. It (SRM) is engaging proactively with the most strategic suppliers to capture innovation, jointly develop new products and services, improve the operational efficiency and speed up the time to market that requires a much broader and more relationship based approach. SRM is based on a 10 key strategic roadmap; create supplier development team, supplier participation in new product development, training of suppliers, loaning key employees to suppliers, share the savings, joint process development, improve joint account/invoicing systems, join development of technology roadmap, risk sharing, and joint development of metrics. A common word in the above 10 areas is "joint" that is based on mutual respect.

Poirier, Quinn and Swink (2010) show the rank of degree of collaboration and profit per vehicle. Profits per vehicle for Nissan, Honda and Toyota are far superior to those of American made automobiles. While Ford and GM experienced a negative return, all Japanese car makers show greater profit level than their counterpart in the United States. Although this paper does not claim that SRM alone contributed to a greater profit level, it is rather hard not to ignore such factor. Incidentally, the relationship between the SRM rank and profit rank is statistical significant $(\mathrm{p}<0.05)$.

Henke, Stalkamp and Yeniyurt (2014) provided the most comprehensive research findings linking the level of trust with profit per vehicle basis. The study constructed supplier trust index of Chrysler's vehicle and related this index with operating income (EBIT). The results clearly show in graphical form that trust index and operating income move very closely together indicating trust indeed affects the operating income. In addition, the study reveals supplier's non-price contribution to Chrysler operating income in such areas as increased supplier willingness to share new product and process innovation ideas with the customer, increased supplier willingness to invest in customer specific new product and process innovation in anticipation of future customer's needs, greater supplier willingness to allocate greater resources and the most qualified personnel to support the customer, and more open and honest supplier communication with the customer. The increased supplier nonprice benefit contributed to more efficient and effective operations within Chrysler that resulted in lower operational costs. These, in turn, resulted in supplier-related profit contributions of up to 8 times the price concessions that suppliers provided Chrysler. An interesting result is that the stronger the customer demand price reduction, less the suppliers willing to consent. There is a clear inverse relationship between these two areas. The paper argues that had Chrysler used supplier relationship management model called SCORE that launched in 1999 but abandoned in 2007, Chrysler would have made $\$ 688$ additional profit per light vehicle made since 2001. This additional profit/per vehicle would have resulted in Chrysler realizing a total gain of almost $\$ 24$ billion in additional operating income. A similar finding was reported by John (2014).

\section{SUMMARY AND CONCLUSION}

Collaborative relationships in supply chain have been known for many years as the single most important factor for sustainable and profitable operations. Theory seems to suggest that trust based collaboration reduces transaction cost and improves overall business efficiency. In addition, such a 
relationship also improves the speed to market thereby enhancing the global brand name recognition and contributes to capitalizing the market share. Cost reduction and improved market capitalization would release some of the supply chain "surplus" to invest in areas where further innovation is financially feasible. The positive cycle will continue.

Such theoretical argument has been tested and proved to some extent by several empirical researches over the last few years. A study by Henke, Stalkamp and Yeniyurt (2014) is the most comprehensive and convincing research outcome. They highlighted how much Chrysler lost due to a lack of trust with suppliers. A study by Aberden Group (2011) shows cash conversion cycle, speed of invoice process and more generous term of credit extension are far superior for companies that practice relationship management than those who rely less on such tools. Similar positive results are also reported in the areas of inventory management, administrative cost, logistics optimization and production cost (Duffy, 2009). It is, then, not unexpected to see the return on capital for such companies is much better than other companies (Cotton, 2009).

Nevertheless, a challenge still remains in methodologies of measuring the level of trust and collaboration. Empirical research cited above used different scale and constructs measuring the level of trust and collaboration. Perhaps research on standardized measurement scale on trust and relationship may solve some of the issues that we face. It would be a worthwhile research topic to further our understanding of this complex relationship.

\section{MANAGERIAL IMPLICATIONS}

Supply chain has been widely used over the last two decades. Information technologies have been a significant contributor to such advancement of supply chain maturity and a recent addition of cloud-computing will accelerate our understanding of complex supply chain operations. But many supply chain practitioners as well as researchers seem to jump to tools without a solid foundation. No wonder why so many supply chain practitioners have been left cold and disappointed in spite of huge investments into information technologies. In addition, we have to ask ourselves why it is so hard to experience a sustainable supply chain operation.

This paper suggests that a solution is in the supply chain foundation that addresses the importance of relationship. Many research studies show there is a close correlation between the degree of collaborative relationship and financial rewards. Without a solid foundation, the supply chain is unable to cope with supply chain operations that have become ever more complex, global, dynamics and innovative. This paper seems to shed a warning suggesting not to waste resources unless we have a solid supply chain foundation. It is, therefore, advisable for supply chain managers to start with foundation and sound collaborative relationship with partners before launching ambitious goals that take enormous resources to see only less than expected success or even failure. 


\section{REFERENCES}

Ampula, White, Ventatesh, \& Dubey. (2014, September-October). Packaging: think inside and outside the box. Supply Chain Management Review, 30-39.

Barney, J. B., \& Hansen, M. H. (1994). Trustworthiness as a source of competitive advantage. Strategic Management Journal, 15(S1), 175-190. doi:10.1002/smj.4250150912

Benavides, L., Eskinazis, V. D., \& Swan, D. (2012). Six steps to successful supply chain collaboration. CSCMP's Supply Chain Quarterly, Q2, 23-25.

CAPS Research. (2013). Value chain collaboration. CAPS Research in Supply Management, 24(6), 34-35.

Chang, V., \& Wills, G. (2013). A University of Greenwich Case Study of Cloud Computing. In E-Logistics and E-Supply Chain Management: Applications for Evolving Business. Academic Press.

Cheung, S. N. S. (1987). Economics organization and transactions costs. The New Palgrave: A Dictionary of Economics, 2, 55-58.

Coase, R. (1937). The nature of the firm. Economica, 4(16), 386-405. doi:10.1111/j.1468-0335.1937.tb00002.x

Cotton, B. (2009, October). Meetings around the world II: charting the course of advanced collaboration. Frost \& Sullivan.

Covey, S. (2008). Speed of Trust. Free Press.

Duffy, M. (2009, September). Is supply chain cure for the rising healthcare cost? Supply Chain Management Review, 28-35.

Dyer, J. (1997). Effective interfirm collaboration: How firms minimize transaction costs and maximize transaction value. Strategic Management Journal, 18(7), 535-556. doi:10.1002/(SICI)1097-0266(199708)18:7<535::AIDSMJ885>3.0.CO;2-Z

Dyer, J., \& Chu, W. (2003). The role of trustworthiness in reducing transaction costs and improving performance: Empirical evidence from the United States, Japan and Korea. Organization Science, 14(1), 57-68. doi:10.1287/ orsc.14.1.57.12806

Eshkenazi, A. (2009). APICS Operations Management Now. APICS Homepage.

Fawcett, Andrawski, Fawcett, \& Magnan. (2009, November). The art of supply chain management. Supply Chain Management Review, 19-25.

Giguere \& Householder. (2012, November). Supply chain visibility: more trust and technology. Supply Chain Management Review, 20-25.

Handfield, R. B., \& Bechtel, C. (2002). The role of trust and relationship structure in improving supply chain responsiveness. Industrial Marketing Management, 31(4), 367-382. doi:10.1016/S0019-8501(01)00169-9

Henke, Stalkamp, \& Yeniyurt. (2014, May-June). Lost supplier trust and lost profit. Supply Chain Management Review, 24-32.

Hennart, J. F., \& Anderson, E. (1993). Countertrade and the minimization of transaction costs: An empirical examination. Journal of Law Economics and Organization, 9(2), 290-313.

John, G. (2014, August). At long last, proof that supplier relationship management pays off. SCM World.

Kwon, Hong, \& Hamilton (2011). Trust and transaction cost in supply chain cost optimization: An exploratory study. In Inter-Organizational Information Systems and Business Management: Theories for Researchers. IGI Global.

Kwon, I.-W., \& Hong, S.-J. (2011). Health care supply chain management in the United States: New paradigm for roles of distributors. International Journal of Health Management and Information, 2(2), 73-82.

Kwon, I.-W., \& Suh, T. (2005). Trust, commitment and relationships in supply chain management: A path analysis. Supply Chain Management: An International Journal, 10(1), 26-33. doi:10.1108/13598540510578351 
Kwon, I.-W. G., \& Suh, T. (2004). Factors affecting the level of trust and commitment in supply chain relationships. The Journal of Supply Chain Management, 40(2), 4-14. doi:10.1111/j.1745-493X.2004.tb00165.x

Lambert, L. M. C., \& Pagh, J. (2001). Supply chain management: Implementation issues and research opportunities. The International Journal of Logistics Management, 12(2), 1-19. doi:10.1108/09574090110806190

McGrath \& Sparke. (2005). The importance of building social capital. Quarterly Progress, 38(2), 45-49.

Monczka, R. M. (2014). CAPS Research. Arizona State University.

Myhe, N., \& Speckman, R. R. (2005). Collaborative supply chain partnerships built upon trust and electronically mediated exchange. Journal of Business and Industrial Marketing, 20(4/5), 179-186. doi: $10.1108 / 08858620510603855$

North, D. C. (1990). Institutions, Institutional Change and Economic Performance. Cambridge, UK: Cambridge University Press. doi:10.1017/CBO9780511808678

O’Marah, K. (2012, December). The missing link in S\&OP: flexibility pricing. SCM World Research Report, 4.

Pekman, R. E., Kamauff, J. W., \& Myhr, N. (1998). An empirical investigation into supply chain management: A perspective on partnership. Supply Chain Management, 3(2), 53-67. doi:10.1108/13598549810215379

Poirier, Quinn, \& Swink. (2010). Diagnosing Greatness. Ross Publication.

Robinson, A. (2015, November 23). 5 big benefits of could-based supply chain management systems. Cerasis Blog.

Simatupang, T. M., \& Sridharan, R. (2005). The Collaboration index: A measure for supply chain collaboration. International Journal of Physical Distribution \& Logistics Management, 35(1), 44-62. doi:10.1108/09600030510577421

Stallkamp, T. (2005). Score! A Better Way to Do Business. Prentice Hall.

Suh, T., \& Kwon, I.-W. (2003). The role of bilateral asset specificity and replaceability on trust in supply chain partner. Proceedings in the American Marketing Association Winter Conference.

Tadelis, S. (2007). The innovative organization: Creating value through outsourcing. California Management Review, 50(1), 261-277. doi:10.2307/41166427

Themistcloeous, M., Irani, Z., \& Love, P. E. D. (2004). Evaluating the integration of supply chain information systems: A case study. European Journal of Operational Research, 159(2), 393-405. doi:10.1016/j. ejor.2003.08.023

UPS. (2015). Embracing the risk: It is the time to capitalize the untapped opportunities. The Seventh Annual Pain in the (Supply) Chain Survey. UPS.

Whitney, J. (1994). The Trust Factor: Liberating Profits and Restoring Corporate Vitality. McGraw-Hill.

Williamson, O. (1981). The economics of organizations: The transaction cost approach. American Journal of Sociology, 87(3), 548-577. doi:10.1086/227496

Williamson, O. (2008). Outsourcing: Transaction cost economics and supply chain management. Journal of Supply Chain Management, 44(2), 5-16. doi:10.1111/j.1745-493X.2008.00051.x

Xie, Y. H., Suh, T., \& Kwon, I.-W. (2010). Do magnitude and asymmetry of specific asset investment matter in supplier-buyer relationship? Journal of Marketing Management, 23(1), 1-20. 